\title{
Case study on measuring the level of stress in the academic environment in France
}

\author{
L C Dascalu ${ }^{1}$, O Chivu ${ }^{1}, \mathrm{C}_{\text {Babiş }}{ }^{1}$, A Dimitrescu ${ }^{2}$ and $\mathrm{E} \mathrm{Niculae}^{2}$ \\ ${ }^{1}$ Welding and Material Technology Department, Politehnica University of Bucharest, Romania \\ ${ }^{2}$ Theory of Mechanisms and Robots Department, Politehnica University of Bucharest, \\ Romania \\ Dascalu_loredana_cristina@yahoo.com
}

\begin{abstract}
The study is a novelty because was elaborated on a group of students in the academic environment in France. Following the documented steps, I have noticed that several questionnaires have been used in order to identify stress levels in the academic environment. The case study presented in this article consists in a questionnaire meant to identify stress factors. There are several factors that are likely to cause stress: changes to routine, time pressure, difficult tasks, too much homework's, financial state, sleep schedule and physical work conditions. I believe that stress management results could be visible if we can motivate people to adjust their behavior and life style.
\end{abstract}

Keywords: stress, questionnaires, detection, statistics, MatLab

\section{Introduction}

The aim of this study is to detect the stress in the academic environment in France. I applied the following instrument: The Holmes and Rahe Scale Questionnaire, to identify stress factors.

This study was conducted during three months in France on a group of 76 students of different universities. Stress at work has become a serious problem affecting many people of different professions and students as well [1].

Stress represents the basis of research for a multitude of doctoral theses and scientific articles. Therefore, over the course of time, stress has been defined in various ways: Stress has a different meaning for different people under different conditions.

The first definition of stress is that proposed by Hans Selye: Stress is the non-specific response of the body to any demand. Other definitions, reviewed in detail by him in his Stress in Health and Disease (1976), include the following:

- In the behavioral sciences, stress is regarded as the "perception of threat, with resulting anxiety discomfort, emotional tension, and difficulty in adjustment".

- He says that "stress is not necessarily something bad - it all depends on how you take it. The stress of exhilarating creative successful work is beneficial, while that of failure, humiliation or infection is detrimental [2]". So, the effects of stress depend on one's positive or negative perception over the situation.

The effect of stress on our emotional and physical health can be devastating. In a recent USA study, over $50 \%$ of individuals felt that stress negatively impacted work productivity. Between 19832009, stress levels increased by 10-30\% among all demographic groups in the USA [3].

Psychologist Richard S. Lazarus defined stress as follows: ,a particular relationship between the person and the environment that is appraised by the person as taxing or exceeding his or her resources 
and endangering his or her well-being.” He also states that stress triggers „two critical processes that mediate the person-environment relationship: cognitive appraisal and coping"[4].

"Stress is the body's reaction to a mentally or emotionally disruptive or upsetting condition; to adverse external influences capable of affecting our physical health [5]."

"Job stress can be defined as the harmful physical and emotional responses that occur when the requirements of the job do not match the capabilities, resources, or needs of the worker. Job stress can lead to poor health and even injury.

The concept of job stress is often confused with challenge, but these concepts are not the same [6]". In the figure. 1 it is related the stress causes for students:

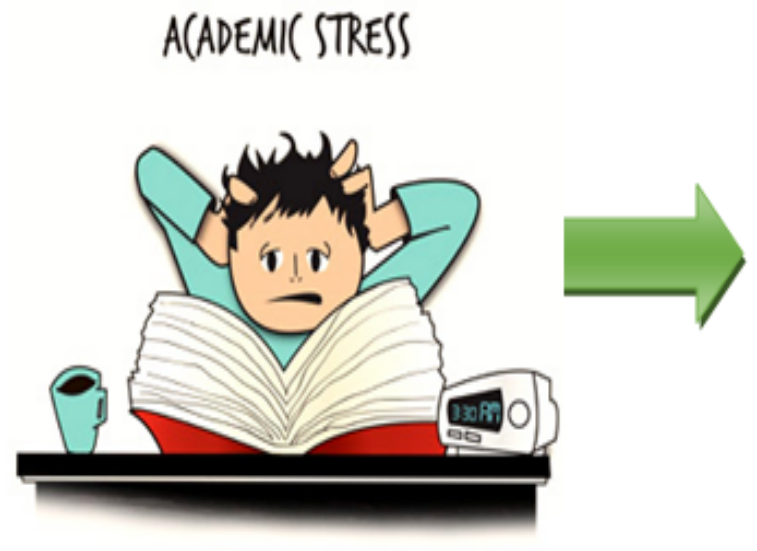

\section{Academic problems and pressures}

Homework

Tests

Bullying

Teachers

Away from home

Rigorous graduate university requirements, standards and expectations

Figure.1. Academic stress for strudents

\section{Measurement results}

In order to verify the validity of the hypotheses and to achieve the objectives that had been previously set, I have used the following tool:

- The Holmes and Rahe Scale Questionnaire (figure.2), to identify stress factors [7].

Mark down the point value of each of these life events that has happened to you during the previous year. Total these associated pointed. Add up all the points you have to find your score.

- 150 pts or less means a relatively low amount of life change and a low susceptibility to stressinduce health problems.

- 150 to 300 pts implies about a 50\% chance of a major stress-induced health problem in the next 2 years.

- 300 pts or more raises the odds to about $80 \%$, according to the Holmes-Rahe prediction model. 


\begin{tabular}{|c|c|}
\hline \multicolumn{2}{|l|}{ Life Event } \\
\hline 1. Death of spouse & 100 \\
\hline 2. Divorce & 73 \\
\hline 3. Marital Separation from mate & 65 \\
\hline 4. Detention in jail or other institution & 63 \\
\hline 5. Death of a close family member & 63 \\
\hline 6. Major personal injury or illness & 53 \\
\hline 7. Marriage & 50 \\
\hline 8. Being fired at work & 47 \\
\hline 9. Marital reconciliation with mate & 45 \\
\hline 10. Retirement from work & 45 \\
\hline 11. Major change in the health or behavior of a family member & 44 \\
\hline 12. Pregnancy & 40 \\
\hline 13. Sexual Difficulties & 39 \\
\hline 14. Gaining a new family member (i.e. birth, adoption, older adult moving in, etc.) & 39 \\
\hline 15. Major business adjustment & 39 \\
\hline 16. Major change in financial state (i.e. a lot worse or better than usual) & 38 \\
\hline 17. Death of a close friend & 37 \\
\hline 18. Changing to a different line of work & 36 \\
\hline 19. Major change in number of arguments with spouse (i.e. a lot more or less) & 35 \\
\hline 20. Taking on a mortgage (for home, business, ete.) & 31 \\
\hline 21. Foreclosure on a mortgage or loan & 30 \\
\hline 22. Major change in responsibilities at work (i.e. promotion, demotion, etc.) & 29 \\
\hline 23. Son or daughter leaving home (marriage, college, military, etc.) & 29 \\
\hline 24. In-law troubles & 29 \\
\hline 25. Outstanding personal achievement & 28 \\
\hline 26. Spouse beginning or ceasing work outside the home & 26 \\
\hline 27. Beginning or ceasing formal schooling & 26 \\
\hline 28. Major change in living condition (i.e. new home, remodeling, deterioration, etc.) & 25 \\
\hline 29. Revision of personal habits (i.e. dress, associations, quit smoking, ete.) & 24 \\
\hline 30. Troubles with the boss & 23 \\
\hline 31. Major changes in working hours or conditions & 20 \\
\hline 32. Changes in residence & 20 \\
\hline 33. Changing to a new school & 20 \\
\hline 34. Major change in usual type and/or amount of recreation & 19 \\
\hline 35. Major change in church activity (i.e. a lot more or less) & 19 \\
\hline 36. Major change in social activities (i.e. clubs, movies, visiting, etc.) & 18 \\
\hline 37. Taking on a loan (i.e. car, tv, freezer, ete.) & 17 \\
\hline 38. Major change in sleeping habits (i.e. a lot more or less) & 16 \\
\hline 39. Major change in number of family get-togethers (i.e. a lot more or less) & 15 \\
\hline 40. Major change in eating habits (i.e. a lot more or less, eating hours, surroundings, etc) & 15 \\
\hline 41. Vacation & 13 \\
\hline 42. Major holidays & 12 \\
\hline 43. Minor violations of the law (i.e. traffic tickets, jaywalking, etc.) & 11 \\
\hline
\end{tabular}

Figure 2. Holmes-Rahe questionnaire

\section{Interpretation of measurement results}

In this case study, there have been 76 respondents aged aged 18 to 55, who took part in this study. The age distribution was the following: $63 \%$ of respondents aged 18 to $25,25 \%$ of respondents aged 26 to $35,8 \%$ of respondents aged 36 to 45 , and $4 \%$ aged 46 to 55 .

In that which concerns gender, out of the total amount of respondents, 14 of them were males $(18 \%)$ and 62 were females (82\%).The research took place between May and July 2014 and the respondents came from universities situated in Paris and Evry Île-de-France (France). A short description of Matlab software are presented in figure.3.

This is an example of a calculation procedure for Holmes-Rahe Questionnaire with Matlab software (figure.4):

Holmes_Fr=xlsread('anova.xlsx',' HolmesFr')

mean(Holmes_Fr)

var(Holmes_Fr)

std(Holmes_Fr) 

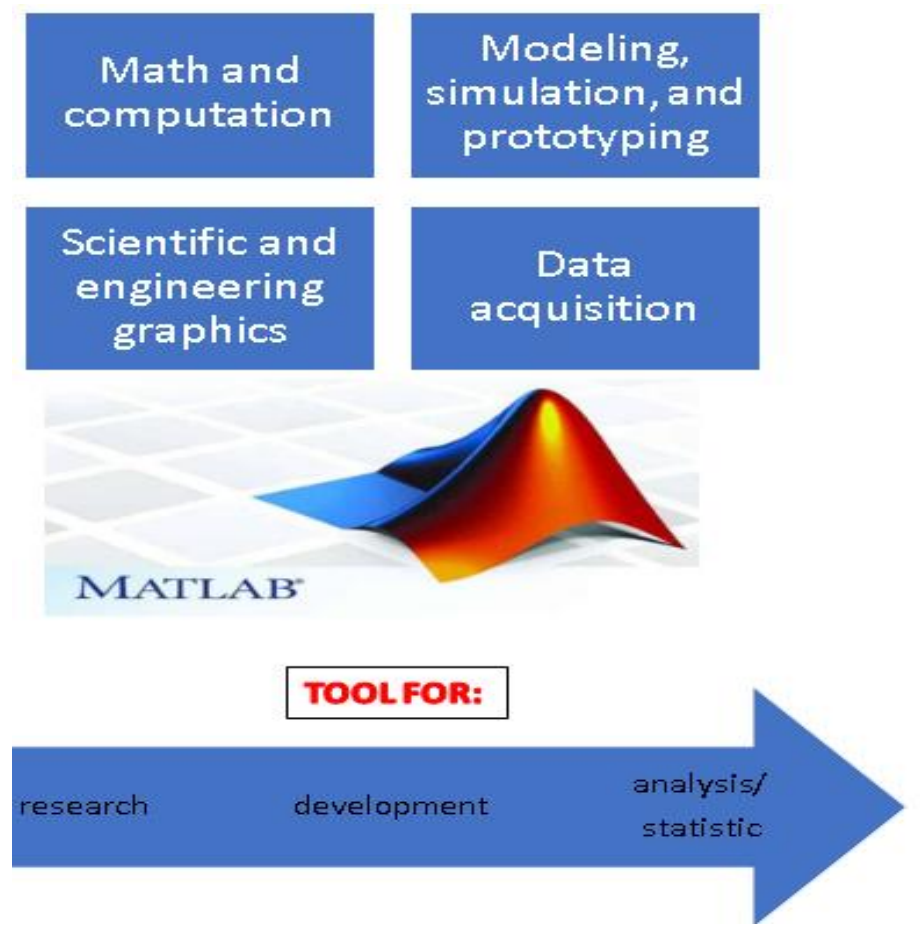

Figure 3. MatLab software description

The average score for the group of respondents was extremely high, of approx. 1266 points. Therefore, it may be concluded that the subjects who took part in this interview may consider stress a health issue and may be exposed to a major risk of stroke or mental illness.

Out of the 76 respondents, only one (approx. 1.32\%) scored below 150 points (135 points), thus presenting a low risk of illness. Another respondent (approx. 1.32\%) scored between 150 and 299 points (284 points), thus presenting a moderate risk of illness (a 50\%) probability of stress turning into a health issue). The other 74 respondents (approx. 97,37\%) scored above 300 points, thus presenting a high risk of illness (a $90 \%$ probability of stress turning into a health issue) [8].

Representation of the corresponding average to the Holmes-Rahe Questionnaire is presented in fig.5. Below there are the meanings of the Matlab functions used to calculate the statistic indicators (Table.1) - theoretical average, standard deviation, variance:

- mean = average;

- $\operatorname{var}=$ variance/dispersion;

- $\operatorname{std}=$ standard deviation .

Tabel.1. Result for Holmes-Rahe Questionnaire

\begin{tabular}{|l|r|}
\hline Respondent & Holmes -Rahe Questionnaire \\
\hline $\mathbf{1}$ & 2691 \\
\hline $\mathbf{2}$ & 6434 \\
\hline $\mathbf{3}$ & 3803 \\
\hline $\mathbf{4}$ & 551 \\
\hline $\mathbf{5}$ & 1199 \\
\hline $\mathbf{6}$ & 866 \\
\hline $\mathbf{7}$ & 877 \\
\hline $\mathbf{8}$ & 348 \\
\hline
\end{tabular}




\begin{tabular}{|l|r|}
\hline Respondent & Holmes -Rahe Questionnaire \\
\hline $\mathbf{9}$ & 966 \\
\hline $\mathbf{1 0}$ & 932 \\
\hline $\mathbf{1 1}$ & 445 \\
\hline $\mathbf{1 2}$ & 284 \\
\hline $\mathbf{1 3}$ & 1250 \\
\hline $\mathbf{1 4}$ & 633 \\
\hline $\mathbf{1 5}$ & 1539 \\
\hline $\mathbf{1 6}$ & 1107 \\
\hline $\mathbf{1 7}$ & 1755 \\
\hline $\mathbf{1 8}$ & 1119 \\
\hline $\mathbf{1 9}$ & 416 \\
\hline $\mathbf{2 0}$ & 1189 \\
\hline $\mathbf{2 9}$ & 505 \\
\hline $\mathbf{3 0}$ & 919 \\
\hline $\mathbf{3 1}$ & 1371 \\
\hline $\mathbf{3 2}$ & 1288 \\
\hline $\mathbf{3 3}$ & 1357 \\
\hline $\mathbf{3 4}$ & 848 \\
\hline $\mathbf{3 5}$ & 756 \\
\hline $\mathbf{3 6}$ & 435 \\
\hline $\mathbf{3 7}$ & 815 \\
\hline $\mathbf{3 8}$ & 1405 \\
\hline $\mathbf{3 9}$ & 1506 \\
\hline $\mathbf{. *}$ & $\mathbf{1 6 5 2}$ \\
\hline $\mathbf{7 5}$ & 135 \\
\hline $\mathbf{7 6}$ & $\mathbf{1 2 6 6 , 4 8 7}$ \\
\hline Average (m) & $\mathbf{1 0 2 1 , 5 6 7}$ \\
\hline Standard & \\
\hline deviation $(\boldsymbol{s})$ & $\mathbf{1 0 4 3 5 9 , 8}$ \\
\hline Variance $\left(\boldsymbol{s}^{\mathbf{2}}\right.$ & \\
\hline & \\
\hline
\end{tabular}




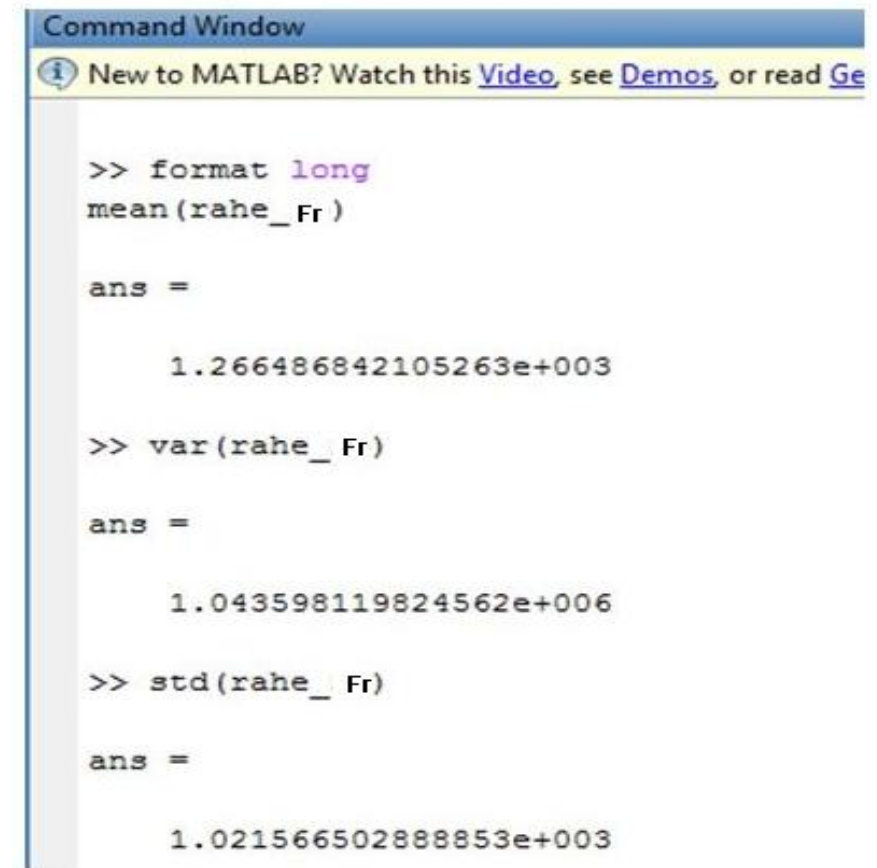

Figure 4. Matlab- statistic indicators

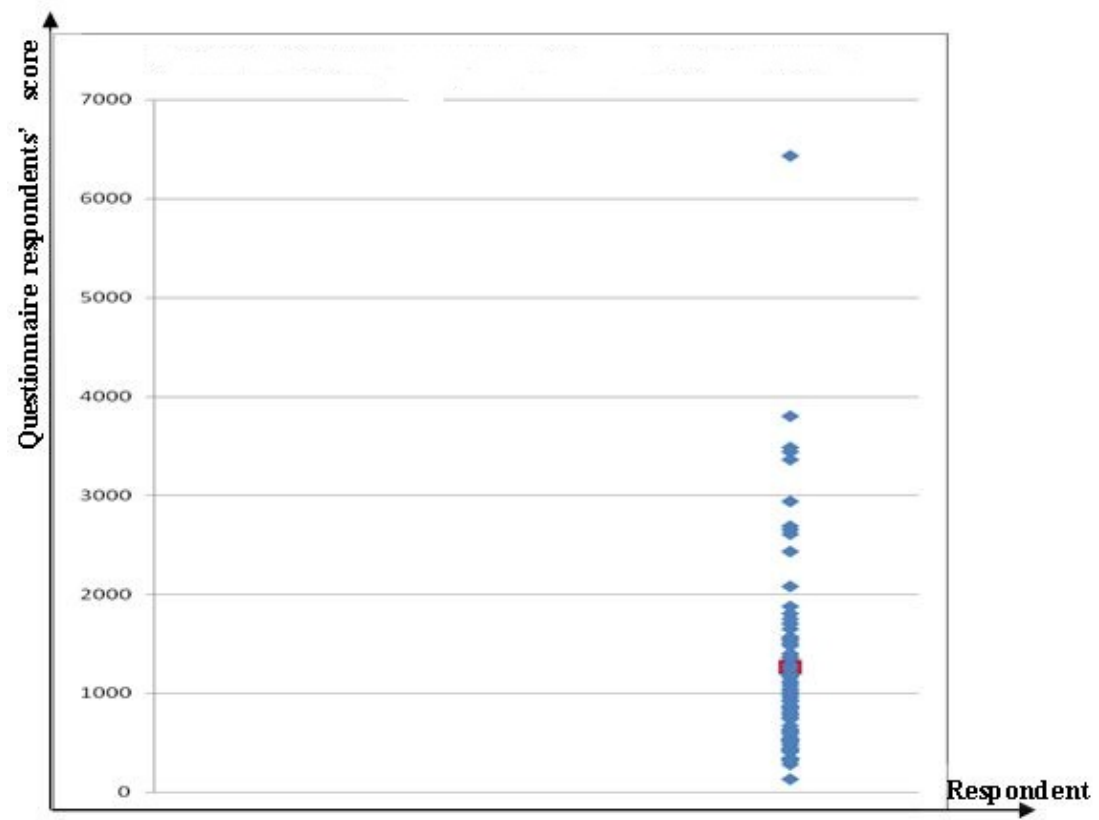

Figure 5. Representation of the corresponding average to the Holmes-Rahe Questionnaire Most stressful life events related with the Holmes and Rahe stress scale it is presented in figure.6. 


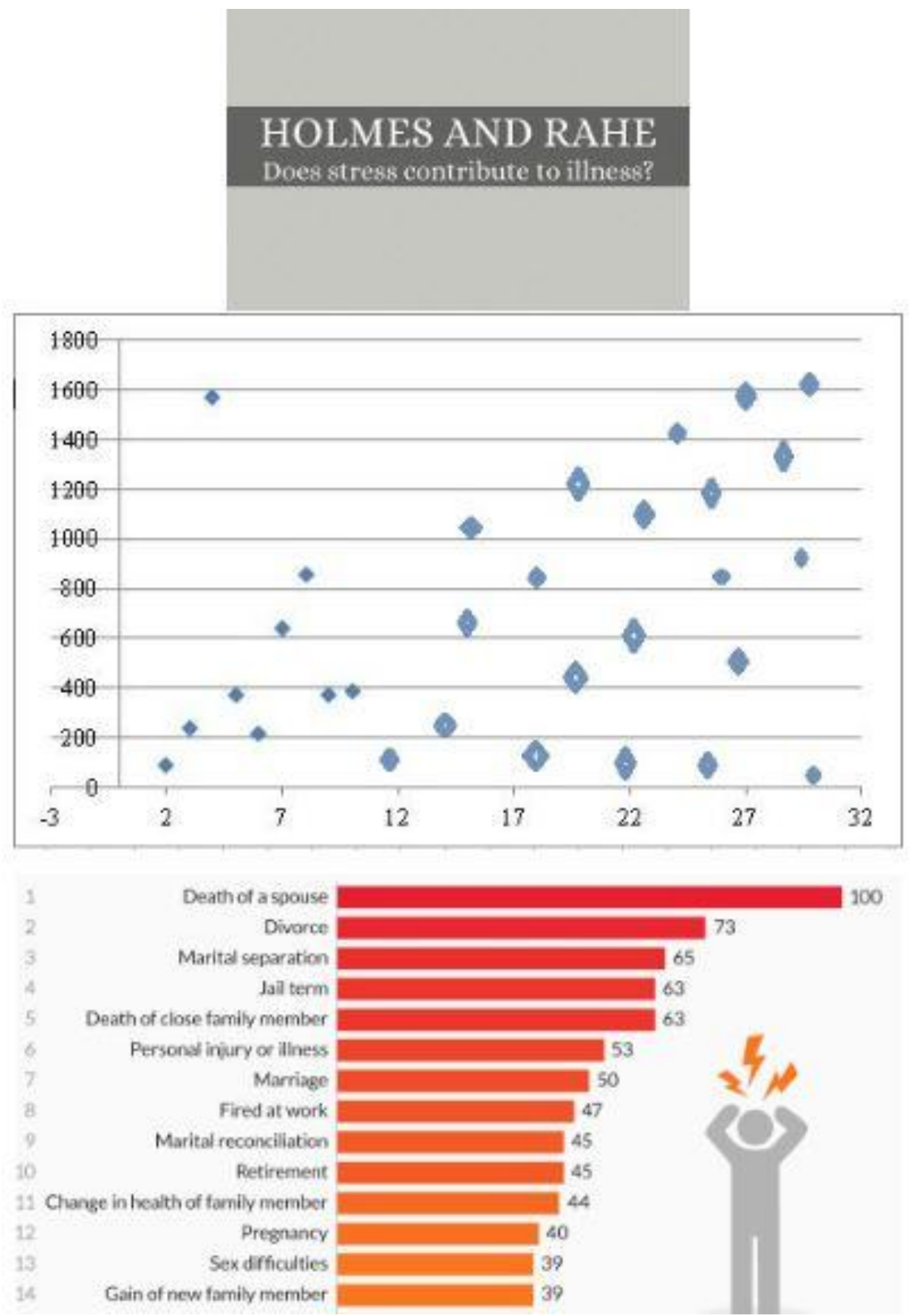

Figure 6. Life events chart

Some of the things students commonly cite as causes of stress include: examinations and pressure of combining paid work and study. In France, they know, that the key to success is to think positively!

\section{Conclusions}

As a conclusion, the average score for the group of respondents to the Holmes-Rahe Stress Scale Questionnaire was exceedingly high, of about 1266 points, and in this case the subjects who took part in this interview may consider stress a health issue and may be exposed to a major risk of stroke or mental illness. The conclusion drawn by analyzing these questionnaire is that the staff in the academic environment is exposed to a high level of stress.

The academic environment is a stress generator due to the fact that, during university, students encounter various situations and they must demonstrate skills to cope with the multitude of challenges that arise, make important decisions in their careers, etc. 
Volume 1, Issue 1, 2019

ISSN: 2668-0416

Thoth Publishing House

Despite there being thousands of treatises about this subject, as well as multiple developments both in theory and in practice, the concept of stress still remains a matter of debate and approaches in this field will continue to be made.

\section{References}

[1] Michie S, Causes and management of stress at work. Occupational and Environmental Medicine 59(1):67, 2002

[2] Selye H, The Stress of Life McGraw-Hill, New York

[3] ***,https://www.researchgate.net/publication/285784528_Stress_Definition_and_history

[4] Lazarus R, Folkman S, Stress Appraisal and Coping Springer New York

[5] ***, http://www.huffingtonpost.com/rita-schiano/stress-triggers_b_878674.html

[6] Sauter S, Murphy L, Colligan M, in The National Institute for Occupational Safety and Health (NIOSH) Publication No. 99-101

[7] Holmes T, Rahe R, Holmes-Rahe Social Readjustment Rating Scale Journal of Psychosomatic Research Vol II

[8] Dascălu L C, Research of the influence of organisational stress levels over the economiv efficciency in integrated management systems Doctoral thesis September 2015 Bucharest Romania 